\title{
Primary thyroid hemangioma: a case report and literature review
}

\author{
Seyed Hossein Fattahi Masuom, Azam Amirian-Far, Reza Rezaei
}

Endoscopic and Minimally Invasive Surgery Research Center, Mashhad University of Medical Sciences, Mashhad, Iran

Kardiochirurgia i Torakochirurgia Polska 2021; 18 (3): 186-189

Hemangioma is a benign vascular neoplasm characterized by capillary proliferation, which is more common in children with a prevalence of $4-5 \%$ [1]. Hemangiomas are more likely to be present in the head and neck region $(65 \%$ of cases) and may occur in any organ of the body, such as the skin, subcutaneous tissue, tongue, brain, and liver, but are extremely rare in the thyroid gland [2]. Most cases of thyroid hemangiomas are secondary to neck procedures such as fine-needle aspiration (FNA) or neck trauma that results from the formation of a hematoma [3].

On the other hand, primary thyroid hemangioma is a developmental anomaly due to the lack of canal formation by angioblastic mesenchyma [4]. These tumors have no obvious clinical manifestations other than cervical mass and no distinct imaging signs are seen with ultrasound or computed tomography (CT) scans. In almost all patients, the diagnosis depends on postoperative histopathology [5]. Here, we report a rare case of thyroid hemangioma in which the retrosternal goiter was suspected preoperatively and review the associated literature.

A 63-year-old man was admitted to the Surgery Department of Ghaem Hospital of Mashhad (Iran) with a history of swelling in the front of the neck for 2 months. The patient had orthopnea and dyspnea on exertion but did not mention other symptoms such as pain over the swelling, hoarseness, dysphagia, or voice change. His past medical history was unremarkable, and also, there was no history of FNA biopsy, neck trauma, ionizing radiation exposure or other intervention in the neck. He had no family history of thyroid disease such as thyroid cancer and was a lifelong non-smoker.

On physical examination, a large goiter was present at the inspection and palpation identified a solid, firm, mobile mass in the thyroid region, which measured about $5 \times 6 \mathrm{~cm}$. The patient had no signs of hypo- or hyperthyroidism and lymphadenopathy. Biochemical and hematological tests showed no abnormal values. Thyroid function tests revealed that the patient was euthyroid.

Ultrasonography of the neck revealed that both thyroid lobes were quite large but had no space-occupying lesions. FNA cytology examination was not performed due to patient disagreement. Also, the neck CT scan of the patient is shown in Figure 1. As a result, based on the evidence obtained, the preoperative clinical diagnosis was a retrosternal goiter.

According to the patient's clinical symptoms, bilateral goiter, and progressive course of the mass, a total thyroidectomy was performed. An intraoperative frozen section was also performed, which an expert pathologist reported as a benign lesion.

Histopathological evaluation of the right lobe showed proliferation of thyroid follicles, most of which contained colloids and cubic cells, surrounded by fibrous tissue and normal thyroid tissue. The histological diagnosis of the right lobe was multinodular goiter. Macroscopic histopathological evaluation of the retrosternal mass revealed a $7 \times 3 \times 0.5 \mathrm{~cm}$ circumscribed hemorrhagic lesion. Microscopic examination showed vascular proliferation with a flat endothelial lining in the context of adipose connective tissue. The final histological diagnosis of the retrosternal mass was cavernous hemangioma.

The patient had no complications after surgery, was followed up for 6 months, and remained asymptomatic.

Hemangioma is a vascular tumor that derives from the endothelial cells. It is more common in children and is generally congenital [6]. Another important point is that hemangiomas are more common in the skin and subcutaneous tissue, and hemangiomas of the thyroid gland are uncommon [2]. Also, thyroid hemangioma is more common secondary to previous neck procedures, so primary thyroid hemangioma is extremely rare and few cases have been reported in the literature. Since our patient did not have a history of FNA or neck trauma, secondary hemangioma was ruled out.

The first case of thyroid hemangioma was reported by Pickleman et al. [7], in 1975, with a mass of $7.5 \times 3.0 \times 2.0 \mathrm{~cm}$ in the left lobe of the thyroid gland. Preoperative diagnosis was made by $99 \mathrm{mTc}$ angiography and the mass was surgically removed [7]. After that, a few other cases were reported that are compared in Table I [4, 5, 7-29].

Patients usually present with swelling or a mass in the front of the neck. The growth rate of this mass has been reported very differently so that in one study, it lasted

Address for correspondence: Reza Rezaei, Endoscopic and Minimally Invasive Surgery Research Center, Mashhad University of Medical Sciences, Mashhad, Iran, phone: 05138012840, fax: 05138402972, e-mail: emis@mums.ac.ir

Received: 14.01.2021, accepted: 16.05.2021. 

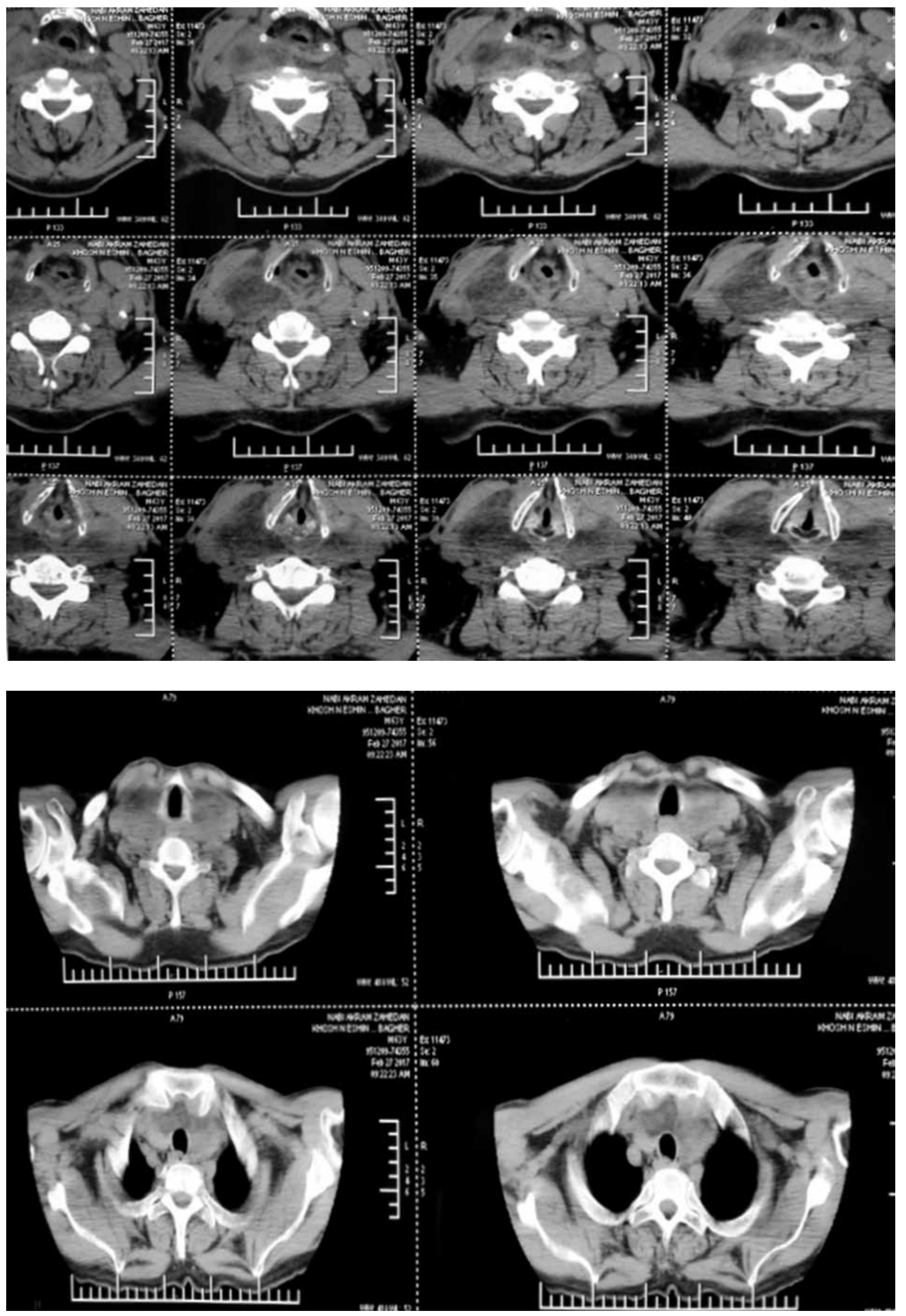

Figure 1. Axial computed tomography scan of the neck 
16 years [20], and another was 20 days after the onset of swelling [27]. In our case, it took two months from the onset of swelling to the onset of symptoms. This gradual increase in mass growth may cause compressive symptoms, such as hoarseness, dyspnea, vocal cord paralysis, dysphagia, voice change, and tracheal deviation [7, 18], as our patient had orthopnea and dyspnea on exertion.

Histologically, thyroid hemangiomas are classified as cavernous, synovial, arteriovenous, venous, capillary, and racemose [17]. As in our case, cavernous hemangioma is the most common, followed by capillary hemangioma (Table I).

Maciel et al. [22] studied thyroid hemangioma size; the largest had weight $2800 \mathrm{~g}$, size $22 \times 21 \times 17 \mathrm{~cm}$, and generally, the diameter varied between 2 and $22 \mathrm{~cm}$. As illustrated in Table I, men were more affected than women, and patients' age ranged from 2 months to 84 years. Also, in most cases, the tumor location was on either the right or left side, while in the study of Liang et al. [27], it was re- ported on both sides and Ishida et al. [11] reported location on the thyroid isthmus.

It is challenging to diagnose thyroid hemangioma before surgery because there are no clinical features or pathognomonic findings on ultrasonography, CT scans or FNA [21]. Although FNA biopsy is essential to diagnose thyroid masses in most cases, it will be inconclusive in hemangiomas because only blood is present in the specimens [21]. However, it is crucial to identify thyroid hemangiomas before surgery because they may lead to significant hemorrhage during surgery. Pickleman et al. [7] reported that the patient lost more than 2 I of blood during left hemithyroidectomy and received four units of whole blood. However, our patient underwent a complete thyroidectomy, but all the thyroid vessels were carefully ligated and the mass was removed without rupture, resulting in minor blood loss.

Shpitzer et al. [30] recommended the use of digital subtraction angiography (DSA), magnetic resonance imag-

Table I. Characteristics of reported cases of thyroid hemangioma

\begin{tabular}{|c|c|c|c|c|c|c|c|}
\hline First author & Year published & Country & Age [years] & Sex & Size $[\mathrm{cm}]$ & Location & Histology \\
\hline Pickleman et al. [7] & 1975 & United States & 56 & Male & $7.5 \times 3 \times 2$ & Left & Cavernous \\
\hline \multirow[t]{3}{*}{ Queiroz et al. [8] } & 1978 & Portugal & 29 & Female & $6.5 \times 4 \times 2.5$ & Right & Cavernous \\
\hline & & & 33 & Male & $9 \times 7 \times 5.5$ & Right & Cavernous \\
\hline & & & 54 & Male & 9 & Right & Cavernous \\
\hline Hernández et al. [9] & 1979 & Spain & 55 & Female & 2 & Right & Capillary \\
\hline Ismaillov et al. [10] & 1981 & Russia & 55 & Male & $10 \times 6 \times 5$ & Right & Cavernous \\
\hline \multirow[t]{3}{*}{ Ishida et al. [11] } & 1982 & Japan & 46 & Male & $14 \times 10 \times 9.5$ & Right & Cavernous \\
\hline & & & 4 & Male & $1.8 \times 0.9 \times 0.3$ & Isthmus & Cavernous \\
\hline & & & 57 & Female & $8 \times 6.5 \times 3$ & Right & Cavernous \\
\hline Yokota et al. [12] & 1991 & Japan & 64 & Female & $7.2 \times 6 \times 4$ & Right & Cavernous \\
\hline Pendse and Porwal [13] & 1998 & India & 53 & Male & $6 \times 3.5$ & Right & Cavernous \\
\hline Kumar et al. [4] & 2000 & India & 53 & Male & $4 \times 4$ & Right & - \\
\hline \multirow[t]{2}{*}{ Rios et al. [14] } & 2001 & Spain & 63 & Female & $5 \times 3$ & Left & Cavernous \\
\hline & & & 48 & Female & $5 \times 4$ & Left & Cavernous \\
\hline Kumamoto et al. [15] & 2005 & Japan & 56 & Female & $7 \times 6$ & Right & Cavernous \\
\hline Senthilvel et al. [16] & 2005 & Ireland & 24 & Male & $6 \times 5$ & Right & - \\
\hline Kano et al. [17] & 2005 & Japan & 21 & Male & $5.5 \times 3 \times 2$ & Right & Cavernous \\
\hline Lee et al. [18] & 2007 & South Korea & 66 & Male & $17 \times 16.5$ & Left & Cavernous \\
\hline Ciralik et al. [19] & 2008 & Turkey & 64 & Male & $7 \times 6 \times 6$ & Right & Cavernous \\
\hline Datta et al. [20] & 2008 & India & 25 & Male & $4.4 \times 4.9$ & Left & Cavernous \\
\hline Sakai et al. [21] & 2009 & Japan & 71 & Female & $5.2 \times 4.8 \times 3.5$ & Left & Cavernous \\
\hline Michalopoulos et al. [5] & 2012 & Greece & 78 & Male & $4 \times 4$ & Right & Cavernous \\
\hline Maciel et al. [22] & 2011 & Brazil & 80 & Female & $22 \times 21 \times 17$ & Left & Cavernous \\
\hline Gutzeit et al. [23] & 2011 & Switzerland & 84 & Female & - & Left & Cavernous \\
\hline Jacobson et al. [24] & 2014 & Canada & $3 M$ & Female & $3.1 \times 3.7 \times 2.2$ & Right & - \\
\hline Dasgupta et al. [25] & 2014 & India & 38 & Male & $6 \times 5 \times 3$ & Left & Cavernous \\
\hline Miao et al. [26] & 2017 & China & 48 & Male & $4 \times 3.5$ & Right & Cavernous \\
\hline Liang et al. [27] & 2020 & China & $2 M$ & Female & $3 \times 3 \times 1$ & $\begin{array}{l}\text { Both } \\
\text { sides }\end{array}$ & Capillary \\
\hline Yang et al. [28] & 2020 & China & 24 & Female & $3.6 \times 1.2 \times 1.5$ & Left & - \\
\hline Bains et al. [29] & 2020 & Australia & 77 & Female & $6 \times 5.5 \times 5$ & Right & Cavernous \\
\hline
\end{tabular}


ing (MRI), red blood cell (RBC) scans, and single-photon emission computed tomography (SPECT) for preoperative diagnosis of thyroid hemangioma. Also, Kumar et al. [4] suggested a technetium-99 erythrocyte-labeled scan to confirm hemangioma. These investigations were not conducted in our case due to high cost and unavailability. Currently, as in our case, almost all patients have been diagnosed by histopathological evaluation of the excised mass [25].

The treatment of choice for thyroid hemangioma is surgical removal by hemithyroidectomy or total thyroidectomy [26]. Our patient also underwent a total thyroidectomy due to compressive symptoms and retrosternal extension.

In conclusion, our case report and literature review indicated that primary thyroid hemangioma is a rare benign disease, mostly escaping preoperative diagnosis. A definitive diagnosis can be made based on histopathological findings. The treatment of choice for thyroid hemangioma is surgery, which has a good prognosis.

\section{Disclosure}

The authors report no conflict of interest.

\section{References}

1. Krowchuk DP, Frieden IJ, Mancini AJ, Darrow DH, Blei F, Greene AK, Annam A, Baker CN, Frommelt PC, Hodak A, Pate BM, Pelletier JL, Sandrock D, Weinberg ST, Whelan MA. Clinical practice guideline for the management of infantile hemangiomas. Pediatrics 2019; 143: e20183475.

2. DeHart A, Richter G. Hemangioma: recent advances. F1000Research 2019; 8: F1000.

3. Tsang K, Duggan M. Vascular proliferation of the thyroid. A complication of fine-needle aspiration. Arch Pathol Labor Med 1992; 116: 1040-1042.

4. Kumar R, Gupta R, Khullar S, Malhotra A. Thyroid hemangioma: a case report with a review of the literature. Clin Nuclear Med 2000; 25: 769-771.

5. Michalopoulos NV, Markogiannakis H, Kekis PB, Papadima A, Lagoudianakis E, Manouras A. Primary cavernous hemangioma of the thyroid gland. South Med J 2010; 103: 674-675.

6. Léauté-Labrèze C, Harper Jl, Hoeger PH. Infantile haemangioma. Lancet 2017; 390: 85-94.

7. Pickleman J, Lee J, Straus F. II, Paloyan E. Thyroid hemangioma Am J Surg 1975; 129: 331-333.

8. Queiroz L, Brunialti JA, Frazatto JC, de Faria Lopes J. Thyroid hemangiomas AMB Rev Assoc Med Bras 1978; 24: 127-130.

9. Hernández JC, Díez LG, de Pablo Dávila F, Martín MA, Alonso AG, García JM. Capillary hemangioma of the thyroid gland. Med Clin 1979; 73: 285-287.

10. Ismaĭlov A, Shelukhin VI, Toroian IA. Cavernous hemangioma of the thyroid. Khirurgiia 1981; 6: 97.
11. Ishida T, Sato H, Hosono O, lino Y, Hoshino K, Yokoe T. Three cases of hemangioma of the thyroid and review of the literature. J Japan Pract Surg Soc 1983; 44: 688-694.

12. Yokota T, Ishida T, Yokoe T, Kurozumi M, Inuzuka S, Kamoshita N. A case of thyroid hemangioma with recurrent laryngeal nerve palsy and literature review. J Japan Soc Clin Surg 1991; 52: 2876-2880.

13. Pendse A, Porwal KK. Solitary primary haemangioma of thyroid. J Indian Med Assoc 1998; 96: 190

14. Rios A, Rodriguez J, Martinez E, Parrilla P. Cavernous hemangioma of the thyroid. Thyroid 2001; 11: 279-280.

15. Kumamoto K, Sugano K, Hoshino M, Utsumi Y, Suzuki S, Takenoshita S. Cavernous hemangioma of the thyroid. Thyroid 2005; 15: 1199-1201.

16. Senthilvel E, Curran A, Malone DE, Crotty T. Radiology quiz case 1. Primary solitary hemangioma of the thyroid gland. Arch Otolaryngol Head Neck Surg 2005; 131: 461-463.

17. Kano M, Kameyama K, Hosoda Y, Sugino K, Ito K. A cavernous haemangioma of the thyroid gland. J Laryngol Otol 2005; 119: 828-830.

18. Lee J, Yun JS, Nam KH, Chung WY, Park CS. Huge cavernous hemangioma of the thyroid gland. Thyroid 2007; 17: 375-376.

19. Ciralik H, Citil R, Bulbuloglu E, Bakaris S. A patient with a neck mass. Neth J Med 2008; 66: 38-39.

20. Datta R, Venkatesh M, Nilakantan A, Joseph B. Primary cavernous hemangioma of thyroid gland. J Postgrad Med 2008; 54: 147-148.

21. Sakai A, Sugitani I, Yamamoto N, Kawabata K. Hemangioma of the thyroid. Clin Med Ear Nose Throat 2009; 2: 7-11.

22. Maciel LM, Gomes PM, Magalhães PK, Filho FVM, Conti-Freitas LC. A giant primary hemangioma of the thyroid gland. J Clin Endocrinol Metabol 2011; 96: 1623-1624.

23. Gutzeit A, Stuckmann G, Tosoni I, Erdin D, Binkert CA. A cavernous hemangioma of the thyroid gland: first documentation by ultrasound of a rare pathology. J Clin Ultrasound 2011; 39: 172-174.

24. Jacobson D, Nayan S, Macnay R, Maclean J. Intra-thyroidal hemangioma a rare congenital anomaly: case presentation and literature review. Int J Pediatr Otorhinolaryngol 2014; 78: 1779-1783.

25. Dasgupta A, Teerthanath S, Jayakumar M, HS K, Raju M. Primary cavernous haemangioma of the thyroid-a case report. J Clin Diagnostic Res 2014; 8: 151-152.

26. Miao J, Chen S, Li Y, Fu L, Li H. A primary cavernous hemangioma of the thyroid gland: a case report and literature review. Medicine 2017; 96: e8651.

27. Liang Y, Pu R, Huang X, Li S, Chen Y, Tang W. Airway obstruction as the primary manifestation of infantile thyroid hemangioma. Italian J Pediatr 2020; 46: 157.

28. Yang DB, Lan HF, Shi PD, Wang YC, Lu M. Evaluation of thyroid hemangioma by conventional ultrasound combined with contrast-enhanced ultrasound: a case report and review of the literature. J Int Med Res 2020; 48: 0300060520954718

29. Bains HK, Agostinho N, Limmer A, Singh A, Abraham E. Primary cavernous haemangioma of the thyroid: a rare pathology. ANZ J Surg 2020; 90: E188E190.

30. Shpitzer T, Noyek AM, Witterick I, Kassel T, Ichise M, Gullane P, Neligan P, Freeman J. Noncutaneous cavernous hemangiomas of the head and neck. Am J Otolaryngol 1997; 18: 367-374. 